\title{
Improving estimations of phytoplankton class abundances using CHEMTAX
}

\author{
Mikel Latasa* \\ Institut Ciències del Mar (CSIC), Passeig Marítim de la Barceloneta 37-49, 08003 Barcelona, Spain
}

\begin{abstract}
CHEMTAX is a computer program that allows researchers to allocate chl $a$, a proxy for phytoplankton biomass, into different algal groups defined by a suite of pigment markers. The program uses an iterative process to find the optimal pigment:chl a ratios and generates the fraction of the total chl a pool belonging to each pigment-determined group. A major difficulty is the choice of initial or seed ratios, which largely determine the results obtained. To test the sensitivity of CHEMTAX to initial ratios and its effectiveness to quantitatively discriminate the existing phytoplankton groups, 8 different initial matrices of pigment ratios were used on an artificial pigment database of 40 samples built from known pigment ratios. Successive runs of CHEMTAX using the output from each run as the input for the next one led to the correct adjustment of most ratios, greatly improving initial values and, therefore, biomass estimates. The convergence of different pigment ratios with successive runs was always directed towards the true value. This procedure also correctly rejected groups that were not used to build the pigment database but whose pigment ratios were included in the pigment-ratio matrices. Therefore, matrices including most pigment-ratios can be used without the need to check for the presence of all those phytoplankton groups in the natural sample. Lack of convergence also occurred with some of the 8 initial matrices for some phytoplankton groups. Because some indeterminations could not be removed for all initial ratios, the use of several initial seed values is proposed.
\end{abstract}

KEY WORDS: Phytoplankton $\cdot$ Pigment ratios $\cdot$ HPLC $\cdot$ CHEMTAX

- Resale or republication not permitted without written consent of the publisher

\section{INTRODUCTION}

There are several techniques to identify and quantify phytoplankton groups based on morphological, optical, genetical or biochemical properties. However none of them offer all the information of interest or can be carried out routinely. One of these techniques is the use of phytoplankton pigments as markers of broad taxonomic groups, often at the class level such as Cryptophyceae, Prasinophyceae, Dinophyceae, Bacillariophyceae, Pelagophyceae, Prymnesiophyceae or Cyanophyceae. Benefits and caveats of the approach are described by Jeffrey (1997). The potential advantages, however, have led many to incorporate pigment analysis as a core parameter of marine time series such as HOT (Hawai'i Ocean Time-series; Sakamoto et al. 2004), BATS (Bermuda Atlantic
Time Series; Lomas \& Bates 2004), or DYFAMED (Dynamique des Flux Atmosphériques en Mediterranée; Marty et al. 2002).

Following standard basic laboratory practices (Zapata \& Garrido, 1991, Jeffrey et al. 1997, Latasa et al. 2001) pigments are reliably quantified nowadays (Latasa et al. 1996). The step from pigment marker to algal biomass is not trivial, however. Initially, pigment marker concentrations were used as a semi-quantitative indication of group abundance (Jeffrey 1976, Jeffrey \& Hallegraeff 1980, 1987, Gieskes \& Kraay 1986, Klein \& Sournia 1987). The main value of the reported results was to observe the relative changes in phytoplankton community. Because the relative amount of the different pigment markers is not constant, a more ambitious attempt to mathematically quantify the contribution of different classes to the phytoplankton bulk 
Table 1. Initial pigment:chl a ratios entered into CHEMTAX program. 'True' ratios matrix corresponds to values used to build the database. Matrices A-E were artificially generated (see 'Materials and methods'). Matrices G and H derived from Letelier et al. (1993) and Everitt et al. (1990), respectively. Per: peridinin; 19'but: 19'butanoyloxyfucoxanthin; fuco: fucoxanthin; 19'hex: 19'hexanoyloxyfucoxanthin; pras: prasinoxanthin; allo: alloxanthin; zea: zeaxanthin. (-) pigment marker not present (i.e. pigment:chl $a$ ratio $=0.000$ )

\begin{tabular}{|c|c|c|c|c|c|c|c|c|c|c|}
\hline Seed matrix/group & $\mathrm{Chl} C_{3}$ & Per & $19^{\prime}$ but & Fuco & 19 'hex & Pras & Allo & Zea & $\mathrm{Chl} b$ & $\mathrm{Chl}$ a \\
\hline \multicolumn{11}{|l|}{ True ratios } \\
\hline Prasinophytes & - & - & - & - & - & 0.315 & - & 0.010 & 0.945 & 1.000 \\
\hline Dinoflagellates & - & 1.062 & - & - & - & - & - & - & - & 1.000 \\
\hline Cryptophytes & - & - & - & - & - & - & 0.228 & - & - & 1.000 \\
\hline Haptophytes T3 & 0.046 & - & - & - & 1.703 & - & - & - & - & 1.000 \\
\hline Haptophytes T4 & 0.047 & - & 0.246 & 0.585 & 0.538 & - & - & - & - & 1.000 \\
\hline Synechococcus & - & - & - & - & - & - & - & 0.348 & - & 1.000 \\
\hline Diatoms & - & - & - & 0.754 & - & - & - & - & - & 1.000 \\
\hline \multicolumn{11}{|l|}{ Matrix A } \\
\hline Prasinophytes & - & - & - & - & - & 0.630 & - & 0.020 & 1.891 & 1.000 \\
\hline Dinoflagellates & - & 2.124 & - & - & - & - & - & - & - & 1.000 \\
\hline Cryptophytes & - & - & - & - & - & - & 0.457 & - & - & 1.000 \\
\hline Haptophytes T3 & 0.092 & - & - & - & 3.405 & - & - & - & - & 1.000 \\
\hline Haptophytes T4 & 0.095 & - & 0.493 & 1.171 & 1.076 & - & - & - & - & 1.000 \\
\hline Synechococcus & - & - & - & - & - & - & - & 0.695 & - & 1.000 \\
\hline Diatoms & - & - & - & 1.509 & - & - & - & - & - & 1.000 \\
\hline \multicolumn{11}{|l|}{ Matrix B } \\
\hline Prasinophytes & - & - & - & - & - & 0.158 & - & 0.005 & 0.473 & 1.000 \\
\hline Dinoflagellates & - & 0.531 & - & - & - & - & - & - & - & 1.000 \\
\hline Cryptophytes & - & - & - & - & - & - & 0.114 & - & - & 1.000 \\
\hline Haptophytes T3 & 0.023 & - & - & - & 0.851 & - & - & - & - & 1.000 \\
\hline Haptophytes T4 & 0.024 & - & 0.123 & 0.293 & 0.269 & - & - & - & - & 1.000 \\
\hline Synechococcus & - & - & - & - & - & - & - & 0.174 & - & 1.000 \\
\hline Diatoms & - & - & - & 0.377 & - & - & - & - & - & 1.000 \\
\hline \multicolumn{11}{|l|}{ Matrix C } \\
\hline Prasinophytes & - & - & - & - & - & 0.158 & - & 0.005 & 0.473 & 1.000 \\
\hline Dinoflagellates & - & 1.062 & - & - & - & - & - & - & - & 1.000 \\
\hline Cryptophytes & - & - & - & - & - & - & 0.457 & - & - & 1.000 \\
\hline Haptophytes T3 & 0.023 & - & - & - & 0.851 & - & - & - & - & 1.000 \\
\hline Haptophytes T4 & 0.095 & - & 0.493 & 1.171 & 1.076 & - & - & - & - & 1.000 \\
\hline Synechococcus & - & - & - & - & - & - & - & 0.695 & - & 1.000 \\
\hline Diatoms & - & - & - & 0.754 & - & - & - & - & - & 1.000 \\
\hline \multicolumn{11}{|l|}{ Matrix D } \\
\hline Prasinophytes & - & - & - & - & - & 0.640 & - & 0.714 & 0.713 & 1.000 \\
\hline Dinoflagellates & - & 0.464 & - & - & - & - & - & - & - & 1.000 \\
\hline Cryptophytes & - & - & - & - & - & - & 0.372 & - & - & 1.000 \\
\hline Haptophytes T3 & 0.485 & - & - & - & 0.975 & - & - & - & - & 1.000 \\
\hline Haptophytes T4 & 0.223 & - & 0.238 & 0.251 & 0.067 & - & - & - & - & 1.000 \\
\hline Synechococcus & - & - & - & - & - & - & - & 0.673 & - & 1.000 \\
\hline Diatoms & - & - & - & 0.536 & - & - & - & - & - & 1.000 \\
\hline \multicolumn{11}{|l|}{ Matrix E } \\
\hline Prasinophytes & - & - & - & - & - & 0.500 & - & 0.250 & 0.750 & 1.000 \\
\hline Dinoflagellates & - & 0.750 & - & - & - & - & - & - & - & 1.000 \\
\hline Cryptophytes & - & - & - & - & - & - & 0.250 & - & - & 1.000 \\
\hline Haptophytes T3 & 0.250 & - & - & - & 0.750 & - & - & - & - & 1.000 \\
\hline Haptophytes T4 & 0.250 & - & 0.500 & 0.500 & 0.500 & - & - & - & - & 1.000 \\
\hline Synechococcus & - & - & - & - & - & - & - & 0.750 & - & 1.000 \\
\hline Diatoms & - & - & - & 0.750 & - & - & - & - & - & 1.000 \\
\hline \multicolumn{11}{|l|}{ Matrix F } \\
\hline Prasinophytes & - & - & - & - & - & 0.043 & - & 0.006 & 0.252 & 1.000 \\
\hline Dinoflagellates & - & 0.556 & - & - & - & - & - & - & - & 1.000 \\
\hline Cryptophytes & - & - & - & - & - & - & 0.523 & - & - & 1.000 \\
\hline Haptophytes T3 & 0.197 & - & - & - & 0.450 & - & - & - & - & 1.000 \\
\hline Haptophytes T4 & 0.177 & - & 0.497 & 0.585 & 0.100 & - & - & - & - & 1.000 \\
\hline Synechococcus & - & - & - & - & - & - & - & 0.627 & - & 1.000 \\
\hline Diatoms & - & - & - & 0.406 & - & - & - & - & - & 1.000 \\
\hline
\end{tabular}


Table 1 (continued)

\begin{tabular}{|c|c|c|c|c|c|c|c|c|c|c|}
\hline Seed matrix/group & $\mathrm{Chl} c_{3}$ & Per & $19^{\prime}$ but & Fuco & 19 'hex & Pras & Allo & Zea & $\mathrm{Chl} b$ & $\mathrm{Chl}$ a \\
\hline \multicolumn{11}{|l|}{ Matrix G } \\
\hline Prasinophytes & - & - & - & - & - & 0.470 & - & 0.004 & 1.190 & 1.000 \\
\hline Dinoflagellates & - & 0.666 & - & - & - & - & - & - & - & 1.000 \\
\hline Cryptophytes & - & - & - & - & - & - & 0.500 & - & - & 1.000 \\
\hline Haptophytes T3 & 0.150 & - & - & - & 0.900 & - & - & - & - & 1.000 \\
\hline Haptophytes T4 & 0.150 & - & 1.100 & 0.156 & 0.156 & - & - & - & - & 1.000 \\
\hline Synechococcus & - & - & - & - & - & - & - & 0.476 & - & 1.000 \\
\hline Diatoms & - & - & - & 1.250 & - & - & - & - & - & 1.000 \\
\hline \multicolumn{11}{|l|}{ Matrix H } \\
\hline Prasinophytes & - & - & - & - & - & 0.238 & - & 0.010 & 0.495 & 1.000 \\
\hline Dinoflagellates & - & 0.388 & - & - & - & - & - & - & - & 1.000 \\
\hline Cryptophytes & - & - & - & - & - & - & 0.498 & - & - & 1.000 \\
\hline Haptophytes T3 & 0.100 & - & - & - & 0.630 & - & - & - & - & 1.000 \\
\hline Haptophytes T4 & 0.100 & - & 0.625 & 0.053 & 0.053 & - & - & - & - & 1.000 \\
\hline Synechococcus & - & - & - & - & - & - & - & 0.588 & - & 1.000 \\
\hline Diatoms & - & - & - & 0.714 & - & - & - & - & - & 1.000 \\
\hline
\end{tabular}

using a limited number of pigment ratios was applied later by Gieskes et al. (1988), Everitt et al. (1990) and Letelier et al. (1993). These methods had difficulties discriminating the contribution of groups that shared pigment markers. Keeping the pigment ratio approach, a more powerful technique was developed by Mackey et al. (1996). CHEMTAX, a program for estimating algal class abundances from pigment markers, applied matrix factorization to estimate the contribution of phytoplankton pigment groups to total chlorophyll a (chl a). It had the advantage of including variable numbers of pigment:chl a ratios and, therefore, refined the definition of pigment groups.

In their presentation of CHEMTAX, Mackey et al. (1996) detailed very carefully the possible weaknesses of the program. A major difficulty in terms of the program output accuracy and in terms of the problem to be solved is the choice of the initial or seed ratios. As the authors said: 'Since the original problem of dividing the data matrix into pigment ratios and algal class abundances was underdetermined, the choice of the initial pigment ratio matrix largely determines the results obtained...' Therefore, there is a need to obtain the most accurate sample information possible to supply the program with the best initial matrix of pigment ratios. However, researching this type of data is often very difficult and impractical because pigments are habitually used to obtain information about the composition of unknown phytoplankton populations. For instance, genetically based approaches can be very accurate in estimating phytoplankton composition, but they are also time-consuming and their routine use is thus compromised, at least at present. Thus, pigment specialists are confronted with the paradox of requiring information about the composition of phytoplank- ton in order to learn about the pigment composition of phytoplankton groups and, ultimately, the composition of phytoplankton.

In this paper, a procedure to overcome part of this problem is suggested. The combination of different initial seed values and successive runs of CHEMTAX, applying the output from each run as the input for the next run, was used to test the robustness of the final output. The proposed protocol also established a method to estimate the confidence of the data analysis performed.

There are possible intrinsic failures in the use of pigments as qualitative and quantitative markers, e.g. the choice of chlorophyll as a proxy for phytoplankton biomass should be made keeping in mind the limitations of the approach (Kruskopf \& Flynn 2006); the correspondences between pigments and taxa are based on few isolates in some of the groups; and there are uncertainties in the pigment ratios because of changes due to physiological state or intraclass variation. Those problems will not be addressed in this paper.

\section{MATERIALS AND METHODS}

An artificial pigment database of 40 samples was built from selected pigment ratios, hereafter referred to as the 'true' pigment ratios (Table 1) based on the Southern Ocean ratios from Mackey et al. (1996). For each sample, the chl a concentration for each group was randomly generated within a certain range to simulate different abundances of phytoplankton groups, e.g. the chl a concentration randomly generated for dinoflagellates was allowed to vary between 0 and 20 while for diatoms the range was between 0 and 100 . 
Then, the accessory pigment concentrations of a certain group were estimated by multiplying that $\mathrm{chl} a$ value by the true pigment to chl a ratios of that specific group. This procedure was repeated for all the phytoplankton groups of the sample. Then, the total concentration of each pigment for that sample was calculated as the sum of contributions of all groups to each pigment. This process was repeated 40 times to obtain an artificial pigment database of 40 samples with known pigment ratios.

To mimic the real process of encountering a new pigment database without previous information, 8 additional pigment to chl a ratio sets (Matrices A to $\mathrm{H}$ ) were used as seed values (Table 1). The ratio values for those 8 matrices were: double the true ratios (Matrix A), half the true ratios (Matrix B), a mixture of Matrices A and B (Matrix C), random but 'reasonable' ratios (up to 10 times the true ratios) (Matrix D), values of $0.75,0.50$ and 0.25 for dominant, secondary and minor pigments, respectively (Matrix E), a mixture of ratios from the literature (Matrix F), values from Letelier et al. (1993) for the DCM off Hawai'i (Matrix G), and values from Everitt et al. (1990) for the western Equatorial Pacific (Matrix H).

When using ratios from the literature, only the ratios of the phytoplankton groups present in the artificial database were included, i.e. Everitt et al. (1990) used ratios for prochlorophytes and for 'other greens' that have been ignored for this exercise. Also, Everitt et al. (1990) did not distinguish haptophytes T4 (Chrysophyceae with 19 'hexanoyloxyfucoxanthin in Letelier et al. 1993) and, therefore, some adjustments in the initial seed values were required for that group.

An additional $\mathrm{chl} c_{3}$ :chl a ratio was introduced in the definition of haptophytes in all matrices in order to increase the complexity of the matrix. A summary of the pigment matrices shows that dinoflagellate, cryptophyte, Synechococcus and diatom concentrations are based on single pigment ratios, haptophytes T3 on 2 pigment ratios, and haptophytes $\mathrm{T} 4$ and prasinophytes on 3 pigment ratios. Peridinin (per), 19'butanoyloxyfucoxanthin (19'but), prasinoxanthin (pras), alloxanthin (allo) and chl $b$ were markers of individual groups, whereas chl $c_{3}$, fucoxanthin (fuco), 19'hexanoyloxyfucoxanthin (19'hex) and zeaxanthin (zea) were shared by 2 algal groups.

Additional CHEMTAX runs were performed to verify the effect on the results of the inclusion of pigment ratios of absent phytoplankton groups. Two imaginary groups were added to the original matrix, and to Matrices E (completely artificial) and F (ratios from the literature). Group Phyto1 'contained' fucoxanthin and zeaxanthin with 0.4 and 0.2 ratios to $\mathrm{chl} a$, and group Phyto2 contained peridinin and chl $b$ with 0.2 and 0.5 ratios to chl $a$.
CHEMTAX was applied initially using the initial matrices described above as first inputs. Successive runs used the output ratios from the previous runs as inputs. The variables required by CHEMTAX for the calculations were as follows (for the specific meaning of these parameters, refer to Mackey et al. 1997): ratio limits were set to 500 , weighting was 'bounded relative error by pigment', iteration limit $=5000$, epsilon limit $=$ 0.0001 , initial step size $=25$, step ratio $=2$, cutoff step $=30000$, elements varied $=\mathrm{n}$ (all pigments), subiterations $=1$, weight bound $=5$.

\section{RESULTS}

The successive runs of CHEMTAX lead to the correct adjustment of most ratios. Four different types of responses could be observed. Type 1: pigment markers of single groups such as peridinin, zeaxanthin, chl $b$ and alloxanthin correctly adjusted to the real values in less than 10 iterations (Fig. 1a); type 2: pigment markers shared by several groups and correctly adjusted such as fucoxanthin for diatoms and 19'hex for haptophytes T3 (Fig. 1b); type 3: pigment markers shared by several groups and not correctly adjusted such as fucoxanthin and 19'hex for haptophytes T4 (Fig. 1c); type 4: pigment markers of single groups that did not adjust correctly such as $19^{\prime}$ but for haptophytes T4 (Fig. 1c).

\section{Correct adjustment of ratios}

The conditions imposed for CHEMTAX runs were very restrictive in the sense that (1) the difference between measured and predicted pigment composition (epsilon limit) was set very low, (2) with initial step size set to 25 the pigment ratio change was limited to a $1 / 25 \%$ change per iteration, (3) the step ratio was set to 2 , which decreases by a factor of 2 the pigment change (step size) when the residual does not decrease on iteration with the initial step size. Under these conditions it was observed that CHEMTAX runs ended mostly when the step size number passed the cutoff step of 30000 , an upper limit set by the program. This means that the run ended when changes in the residual were less than $1 / 30000$.

Most of the time, the change between the input ratios and the output ratios in the initial CHEMTAX run showed the correct tendency, e.g. when the input ratio was higher than the true ratio, the output produced a lower ratio. However, it almost never reached the true ratio on the first run (Fig. 1). Successive runs solved this problem. Sometimes the output did not show the correct tendency. For instance, 
a

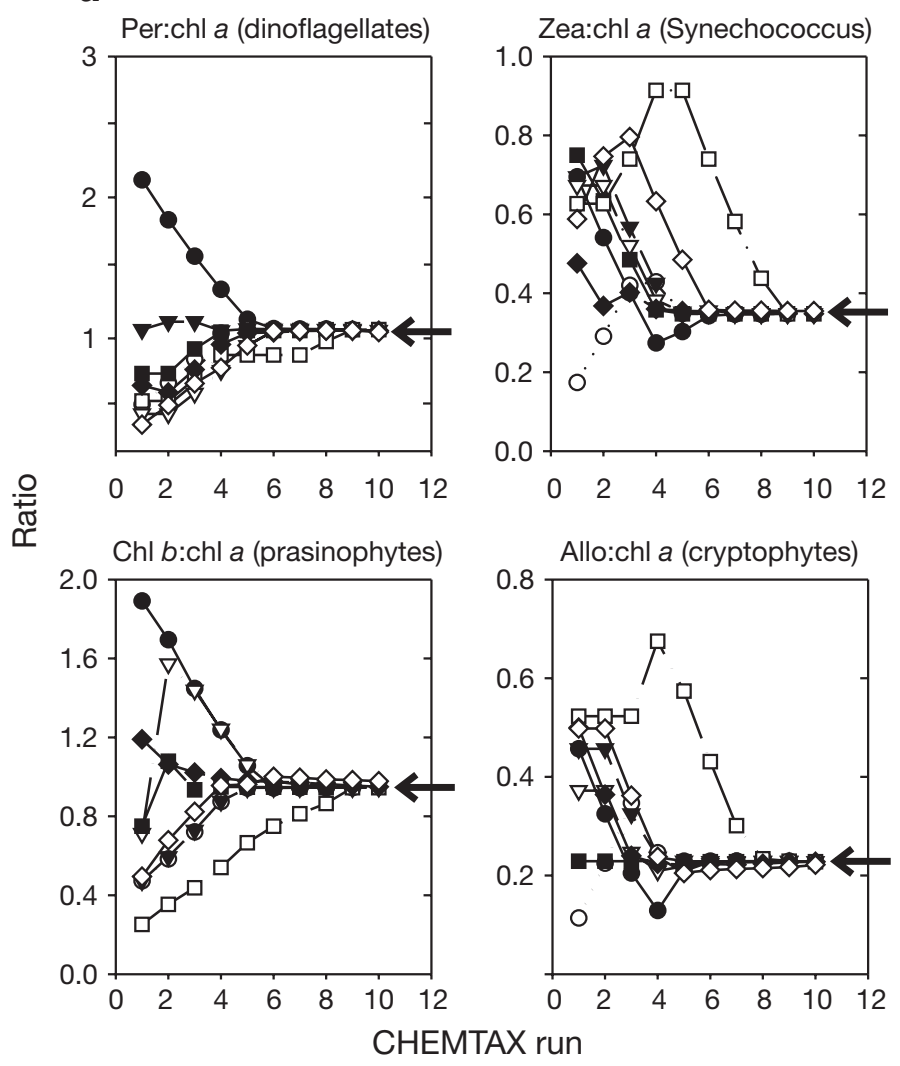

b

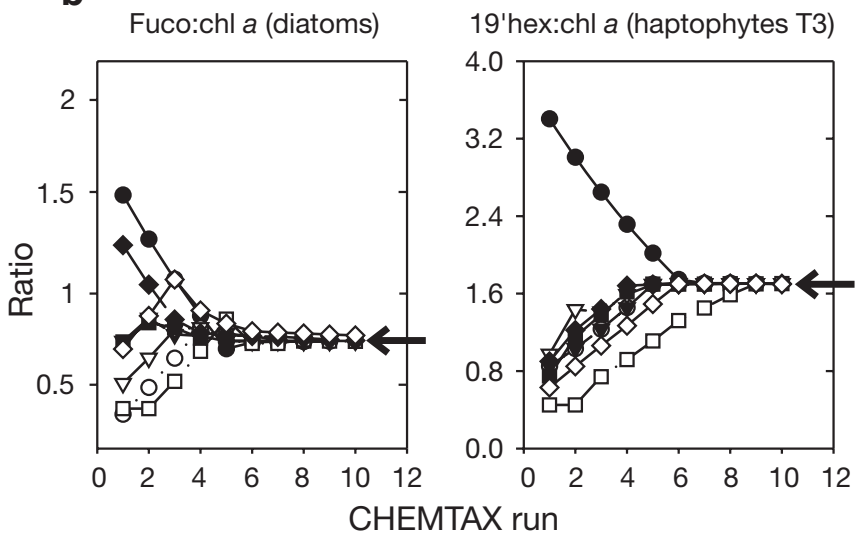

changes in zeaxanthin:chl a for Matrices $\mathrm{C}, \mathrm{F}$ and $\mathrm{H}$ made the values deviate more from the true value in some runs (Fig. 1a). Successive runs again solved this problem.

The program generally encountered no difficulty making ratios converge, including pigment markers of single or multiple phytoplankton groups. In haptophytes T3, a group with shared pigment markers such as chl $c_{3}$ and $19^{\prime}$ hex, the ratios were correctly adjusted.

\section{C}

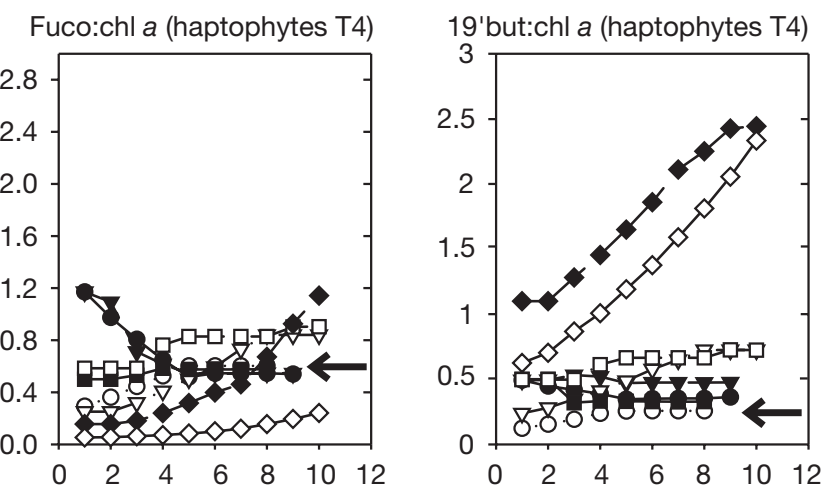

$\stackrel{ㅇ ㅡ ㄹ ~}{\check{D}}$

19'hex:chl a (haptophytes T4)

$\mathrm{Chl} c_{3}: \mathrm{chl} \mathrm{a} \mathrm{(haptophytes} \mathrm{T4)}$
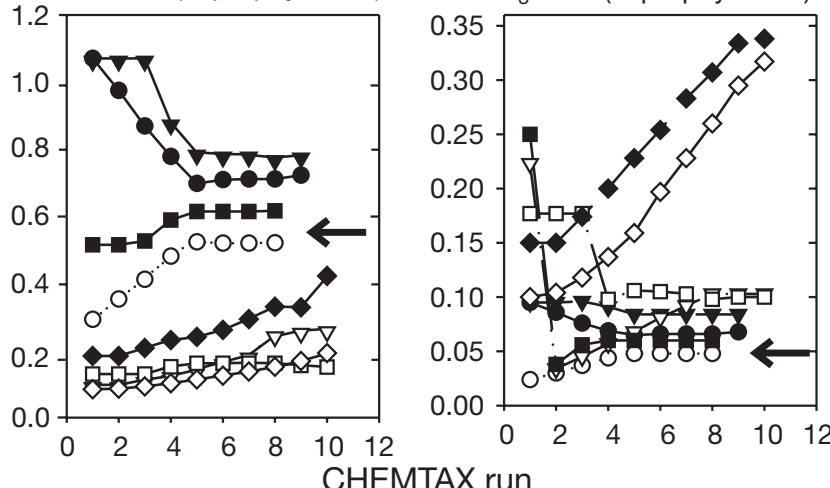

Fig. 1. Evolution of pigment ratios after successive runs of CHEMTAX for different phytoplankton pigment groups. Results for pigment markers (a) of single groups and correctly adjusted, (b) shared by several groups and correctly adjusted, and (c) shared by several groups and not correctly adjusted. For pigment abbreviations, see Table 1. Arrows indicate true ratios (used to build the database)

\section{Incorrect adjustments of ratios}

It became very clear that successive runs of CHEMTAX could not adjust any of the pigment ratios of haptophytes T4 (Fig. 1c). The lack of convergence among the different matrices was conspicuous. It also became evident that in some cases the ratios tended to diverge, reaching values that could be readily discarded as unrealistic, e.g. 19'but:chl a ratios of 2.3 for Matrices G and $\mathrm{H}$ after 10 iterations. Another problem arose when 

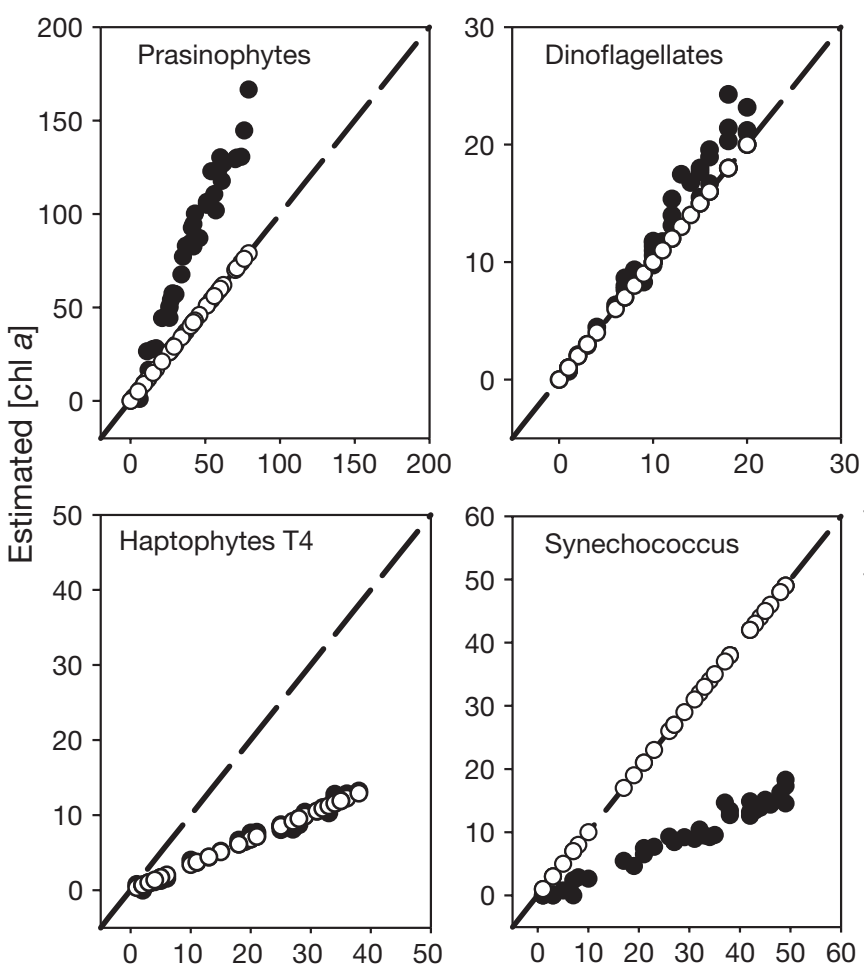

True [chl a]
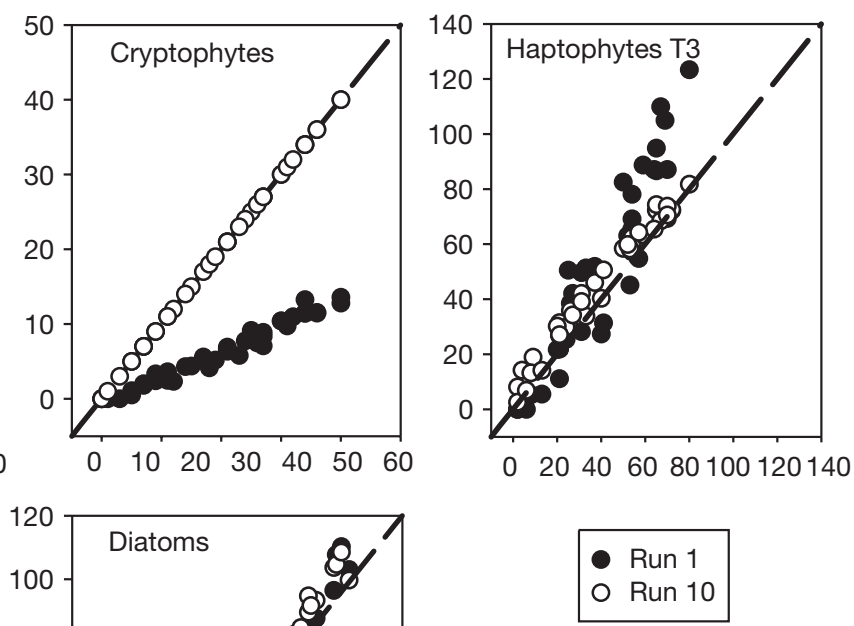

Fig. 2. Comparison of 'true' versus CHEMTAX-estimated values of chl a concentrations for the 1st and 10th run of CHEMTAX. Matrix F was the starting seed matrix the ratios stabilized at values very different to the true ratios. To make things worse, those values were within the range reported in the literature, preventing an objective selection of the optimal value, e.g. 19'hex: chl a ratio for haptophytes T4 (Fig. 1c).

\section{Consequences in biomass estimations}

Matrix F, a mixture of literature values, is an example of how estimations of group biomass can improve with successive runs. Because main pigments drove the estimates of algal group biomass, the program established a good correlation between the real and the estimated chl a equivalent. However, the departure from the true value was evident in the output of the first run (Fig. 2). This deviation decreased with successive runs until the values of the pigment ratios converged with those from other runs using different initial ratios. For Matrix $F$, the changes between runs 9 and 10 were almost null and the biomass estimation for all 7 phytoplankton groups was excellent, except for haptophytes T4. For the latter group, the biomass was underestimated by 50 and $66 \%$ in the first and last run, respectively. Despite these large errors and because of the small contribution of haptophytes T4 to the total biomass, the greatest deviation represented an error of only $12 \%$ in the allocation of the total chl a among the different groups.

\section{Errors in group definition}

Additional CHEMTAX runs were performed to test the inclusion in Matrices $F$ and $E$ of pigment ratios from 2 phytoplankton groups (Phyto1 and Phyto2) that were not used to build the artificial pigment database. These additional ratios comprised pigments that were already present in the former matrices (see 'Materials and methods'). The new groups were given a null biomass after the first run with the original 'true' matrix (data not shown). With both Matrices F and E, the data could adjust quite well after 8 runs (Fig. 3), with less than $5 \%$ chl a allocated to the absent groups. However, the new groups were not immediately excluded by the analysis. Phyto 2 represented almost $20 \%$ of the total chl $a$ in the first run, and Phyto1 still made an important contribution after 5 runs according to CHEMTAX. Obviously, when some chl a was assigned to Phyto1 and Phyto2, other groups with which they shared their pigment ratios were affected, e.g. prasinophytes in Matrix F (Fig. 3).

\section{DISCUSSION}

The successive CHEMTAX runs made the pigment ratios converge to the true ratios for most phytoplankton groups, greatly improving initial estimates and, therefore, biomass estimates. The first run never ren- 


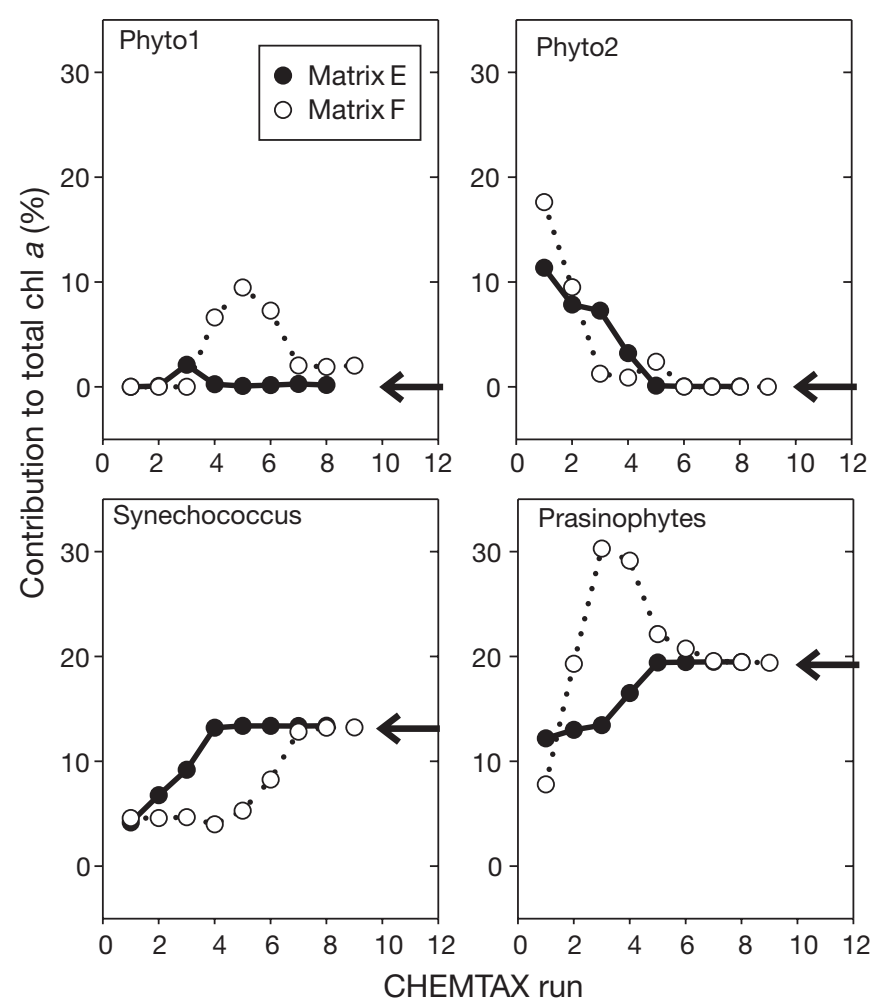

Fig. 3. Effect of the inclusion of groups Phyto1 and Phyto2 in the initial matrices E and F. Those groups did not contribute to the pigment database. Arrows indicate true values

dered the true value, indicating that the program had a limited capacity to adjust the ratios in each run. In their paper, Mackey et al. (1996) pointed out that CHEMTAX might not produce reliable results: (1) when the database contains errors, (2) for minor groups present in the sample, (3) when the seed values are not realistic. In relation to the first point, all pigment concentrations in the database were derived mathematically (see 'Materials and methods'), therefore the methodological errors of analyzing pigments are not considered in the present study. In addition, these errors are usually less than ca. $20 \%$ (Latasa et al. 1996). The consequences of this type of error and how to minimize it are discussed by Mackey et al. (1996). The effect of the approach suggested here on the other 2 causes of error is discussed below.

\section{Minor groups}

It was clear that haptophytes T4 was a troublesome group for the program output. In the database, haptophytes T4 contributed $9.6 \%$ to the total chl $a$, a value lower than that of haptophytes T3 $(19.2 \%)$ or diatoms $(23.2 \%)$, the 2 groups sharing pigments with haptophytes T4. In this sense, it is a minor group. However, it is more abundant than dinoflagellates (5.1\%) and similar to cryptophytes $(9.9 \%)$ and Synechococcus $(13.7 \%)$. Remarkably, 2 of these 3 correctly quantified minor groups were represented by single, not shared pigments. If this last observation could be generalized, only minor groups sharing pigment markers with major groups could be a problem, since minor groups with single markers were correctly quantified.

\section{Unrealistic seed values}

Mackey et al. (1996) limited the 'validity' of CHEMTAX to the use of initial seeds within $25 \%$ of the true value. This is a real limitation if only a single run is performed. Fig. 1 shows that the first run with seed values far departing from the true seed values could not satisfactorily adjust the output ratios. An extreme example of deviating ratios was given by the inclusion of non present phytoplankton groups in the ratio matrix. In this case, the program erroneously assigned an important amount of the total chl a to both Phyto1 and Phyto2 during the first runs when using Matrix E (Fig. 3). However, even under these very adverse conditions, the successive runs of CHEMTAX provided the correct solution by finally assigning an almost null biomass to the non present groups. It should be pointed out that the apparent rejection of the non present phytoplankton groups by the program was only tested for 2 matrices. Although Matrix E could be considered extremely artificial because it was built with only 3 values for all pigment ratios $(0.25,0.5$ and 0.75$)$ and was then used as an extreme example, the possibility cannot be discarded that some untested matrix might assign a significant portion of chl a to the non present groups.

The present study has shown that successive runs with different seed ratios provided a partial solution to 2 main problems for CHEMTAX: the presence of minor groups and the use of unrealistic seed values. In addition, this procedure made clear that when there is a conflict with a group, the conflict is present for all the pigment ratio matrices, as can be seen for haptophytes T4 (Fig. 1c). It should be noted that only the comparison among different initial ratios made the problem evident. The use of successive runs of a single initial matrix would have provided misleading results. In this sense, convergence and stabilization of pigment ratios after successive runs should be differentiated. Convergence of the results from different initial matrices seems a clear indication of a correct ratio. The different initial ratios that stabilized and converged resulted in a true value, and not in an erroneous one. Stabilization, on the other hand, can occur without convergence. For Matrices A to F, the 19'hex:chl a ratio in haptophytes T4 (Fig. 1c) stabilized at different values after several 
runs. Only one of the final ratios is the true value but, unfortunately, the program does not allow us to distinguish which one. When confronted with this problem, only an educated guess can be made for the haptophytes T4 ratios.

This work has proven that a multiple initial ratio approach with successive runs is critical when using CHEMTAX blind, and probably necessary even when additional information on physiology and taxonomy of the studied phytoplankton population is available to infer realistic initial ratios. The convergence after successive runs provides robust evidence of the goodness of fit of the output ratios. It should be clear that this procedure, however, does not guarantee a completely correct output. It seems that minor groups with pigment composition similar to that of larger ones could lead the program to some sort of indetermination.

An alternative explanation for this lack of convergence is that 10 successive runs are not enough iterations to solve our system of non-linear equations. There are several ratios that initially tended to diverge but only to converge later on. Thus, convergence might also occur for haptophytes T4 ratios after hundreds or thousands of iterations were performed. As it is now, CHEMTAX requires several manual steps to format the output file as an input file. Performing this manual procedure hundreds or thousands of times with several initial ratios is unrealistic. Therefore, the approach presented here could be of greater benefit if CHEMTAX is modified to automatically include several initial pigment ratios that are successively run until a convergence criterion is met.

Taking into consideration the above precautionary points, CHEMTAX is a powerful exploratory tool because the convergence of the final pigment ratio seems to be largely determined by the pigment distribution in the data set. There are still unresolved problems for the groups with small pigment contributions. Although apparently a minor problem, it has been shown that some groups make a disproportionate contribution to some biogeochemical cycles in the ocean (Scharek et al. 1999) or to some noxious biological effects (Reguera et al. 1993, Klöpper et al. 2003), so misestimations of biomass for these groups may therefore result in over- or understatement of their biological importance.

Acknowledgements. This work was supported by the EUfunded project PICODIV (EVK3-CT-1999-00021) and the Spanish funded projects COCA (REN-2000-1471-C02) and EFLUBIO (REN2002-04151-C02-01). I thank C. Pedrós-Alió, who encouraged the publishing of these results, and $R$. Scharek who reviewed the initial drafts of the manuscript. Three anonymous reviewers contributed with constructive criticism.

\section{LITERATURE CITED}

Everitt DA, Wright SW, Volkman JK, Thomas DP, Lindstrom EJ (1990) Phytoplankton community compositions in the western equatorial Pacific determined from chlorophyll and carotenoid pigment distributions. Deep-Sea Res 37: 975-997

Gieskes WWC, Kraay GW (1986) Floristic and physiological differences between the shallow and the deep nanophytoplankton community in the euphotic zone of the open tropical Atlantic revealed by HPLC analysis of pigments. Mar Biol 91:567-576

Gieskes WWC, Kraay GW, Nontji A, Setiapermana D, Sutomo D (1988) Monsoonal alternation of a mixed and a layered structure in the phytoplankton of the euphotic zone of the Banda Sea (Indonesia): a mathematical analysis of algal pigment fingerprints. Neth J Sea Res 22:123-137

Jeffrey SW (1976) A report of green algal pigments in the Central North Pacific Ocean. Mar Biol 37:33-38

Jeffrey SW (1997) Application of pigment methods to oceanography. In: Jeffrey SW, Mantoura RFC, Wright SW (eds) Phytoplankton pigments in oceanography: guidelines to modern methods. UNESCO Monogr Oceanogr Methodol, Vol 10, UNESCO Publishing, Paris, p 127-165

Jeffrey SW, Hallegraeff HG (1980) Studies of phytoplankton species and photosynthetic pigments in a warm core eddy of the East Australian Current. I. Summer populations. Mar Ecol Prog Ser 3:285-294

Jeffrey SW, Hallegraeff GM (1987) Phytoplankton pigments, species and light climate in a complex warm-core eddy of the East Australian Current. Deep-Sea Res 34:649-673

Jeffrey SW, Mantoura RFC, Wright SW (1997) Phytoplankton pigments in oceanography: guidelines to modern methods. UNESCO Monogr Oceanogr Methodol, Vol 10, UNESCO Publishing, Paris

Klein B, Sournia A (1987) A daily study of the diatom spring bloom at Roscoff, France, in 1985. II. Phytoplankton pigment composition studied by HPLC analysis. Mar Ecol Prog Ser 37:265-275

Klöpper S, Scharek R, Gerdts G (2003) Diarrhetic shellfish toxicity in relation to the abundance of Dinophysis spp. in the German Bight near Helgoland. Mar Ecol Prog Ser 259: 93-102

Kruskopf M, Flynn KJ (2006) Chlorophyll content and fluorescence responses cannot be used to gauge reliably phytoplankton biomass, nutrient status or growth rate. New Phytol 169:525-536

Latasa M, Bidigare RR, Ondrusek ME, Kennicutt M II (1996) HPLC analysis of algal pigments: a comparison exercise among laboratories and recommendations for improved analytical performance. Mar Chem 51:315-324

Latasa M, van Lenning, K, Garrido JL, Scharek R, Estrada M, Rodriguez F, Zapata M (2001) Losses of chlorophylls and carotenoids in aqueous acetone and methanol extracts prepared for RPHPLC analysis of pigments. Chromatographia 53:385-391

Letelier RM, Bidigare RR, Hebel DV, Ondrusek M, Winn CD, and Karl DM (1993) Temporal variability of phytoplankton community structure based on pigment analysis. Limnol Oceanogr 38:1420-1437

Lomas MW, Bates NR (2004) Potential controls on interannual partitioning of organic carbon during the winter/spring phytoplankton bloom at the Bermuda Atlantic TimeSeries study (BATS) site. Deep-Sea Res I 51:1619-1636

Mackey MD, Mackey DJ, Higgins HW, Wright SW (1996) CHEMTAX - a program for estimating class abundances from chemical markers: application to HPLC measure- 
ments of phytoplankton. Mar Ecol Prog Ser 144:265-283

Mackey MD, Higgins HW, Mackey DJ, Wright SW (1997) CHEMTAX user's manual: a program for estimating class abundances from chemical markers - application to HPLC measurements of phytoplankton pigments. CSIRO Marine Laboratories Report 229, Hobart

Marty JC, Chiaverini J, Pizay MD, Avril B (2002) Seasonal and interannual dynamics of nutrients and phytoplankton pigments in the western Mediterranean Sea at the DYFAMED time-series station (1991-1999). Deep-Sea Res II 49:1965-1985

Reguera B, Bravo I, Marcaillau-LeBaut C, Masselin P, Fernández ML, Miguez A, Martínez A (1993) Monitoring of Dinophysis spp. and vertical distribution of okadaic acid on mussels rafts from Ria de Pontevedra (NW Spain). In:

Editorial responsibility: Otto Kinne (Editor-in-Chief), Oldendorf/Luhe, Germany
Smayda TJ, Shimizu Y (eds) Toxic phytoplankton blooms in the sea. Elsevier, Amsterdam, p 553-558

Sakamoto CM, Karl DM, Jannasch HW, Bidigare RR, and 5 others (2004) Influence of Rossby waves on nutrient dynamics and the plankton community structure in the North Pacific subtropical gyre. J Geophys Res 109: C05032, doi:10.1029/2003JC001976

Scharek R, Latasa M, Karl DM, Bidigare RR (1999) Temporal variations in diatom abundance and downward vertical flux in the oligotrophic North Pacific gyre. Deep-Sea Res I 46:1051-1075

Zapata M, Garrido JL (1991) Influence of injection conditions in reversed-phase high-performance chromatography of chlorophyll and carotenoids. Chromatographia 31: 589-594

Submitted: February 28, 2006; Accepted: June 12, 2006

Proofs received from author(s): December 21, 2006 